\title{
HUBUNGAN ANTARA MOTIVASI BERPRESTASI DENGAN KINERJA GURU AGAMA HINDU JENJANG SEKOLAH DASAR
}

\author{
I Made Wiguna Yasa ${ }^{1}$, I Komang Wisnu Budi Wijaya ${ }^{2}$, I Gede Sudha Cahyana ${ }^{3}$ \\ ${ }^{123}$ Universitas Hindu Negeri I Gusti Bagus Sugriwa Denpasar \\ Email : ${ }^{1}$ wigunayasa1@yahoo.com, ${ }^{2}$ wisnu.budiwijaya240191@ gmail.com, \\ sudha.gede24@gmail.com
}

\begin{abstract}
This research aims to describe the relationship between the achievement motivation and the performance of Hindu religious teachers at elementary school levels who have not been certified as educators. This research is classified as a correlational research. The population of this study were teachers of Hindu religion in elementary schools in Tabanan Regency who had not been certified as educators. The sampling technique used was saturated sampling technique, in which all members of the population were sampled. The research instrument used was an observation sheet of achievement motivation and teacher performance. The data that has been collected were analyzed descriptively and also analyzed by inferential statistics. The analysis of statistic inferential was using a product moment correlation with significant level of 0.05 . The result states that: 1) there is a significant relationship between the achievement motivation and the performance of Hindu religious teachers at elementary school levels who have not been certified as educators ( sig <0,05) and 2) The closeness level of the relationship between achievement motivation and teacher performance is classified as strong $\left(r_{x y}=0,715\right)$.
\end{abstract}

Keywords: Achievement Motivation, Performance, Hindu Religious Teachers, Elementary School

\begin{abstract}
Abstrak
Tujuan dari penelitian adalah untuk mendeskripsikan korelasi antara motivasi berprestasi dengan kinerja guru agama Hindu jenjang sekolah dasar yang belum bersertifikat pendidik. Penelitian ini merupakan penelitian korelasional. Populasi penelitian ini yaitu guru mata pelajaran agama Hindu di sekolah dasar se-Kabupaten Tabanan yang belum bersertifikat pendidik. Pengambilan sampel dilakukan dengan teknik sampel jenuh. Instrumen penelitian yang digunakan berupa lembar observasi motivasi berprestasi dan kinerja guru. Data yang telah dikumpulkan dianalisis secara deskriptif dan statistik inferensial. Analisis statistik inferensial menggunakan korelasi product moment dengan taraf signifikansi 5\%. Hasil penelitian menyatakan bahwa : 1) terdapat hubungan yang signifikan antara motivasi berprestasi dengan kinerja guru agama Hindu sekolah dasar yang belum bersertifikat pendidik (sig < 0,05) dan 2) tingkat keeratan hubungan antara motivasi berprestasi dengan kinerja guru tergolong kuat $\left(\mathrm{r}_{\mathrm{xy}}\right.$ $=0,715)$.
\end{abstract}

Kata Kunci : Motivasi Berprestasi, Kinerja, Guru Agama Hindu, Sekolah Dasar 


\section{PENDAHULUAN}

Dalam Peraturan Pemerintah (PP) No. 55 Tahun 2007 disebutkan bahwa pendidikan agama adalah pendidikan yang memberikan pengetahuan serta membentuk sikap dan keterampilan peserta didik untuk mengamalkan ajaran agamanya melalui mata pelajaran atau mata kuliah pada semua jalur dan jenjang pendidikan. Dalam PP tersebut juga disebutkan bahwa pendidikan agama diberikan kepada peserta didik dengan tujuan untuk mengembangkan sikap peserta didik untuk menghayati dan mengamalkan ajaran agama serta menyesuaikannya dengan perkembangan teknologi. Pengelolalan pendidikan agama diselenggarakan oleh Kementerian Agama.

Pendidikan agama Hindu adalah salah satu pendidikan yang diamanatkan dalam PP No 55 Tahun 2007 (Yasa \& Wijaya, 2020a). Pendidikan agama Hindu dalam kurikulum yang berlaku saat ini diberikan dari jenjang pendidikan dasar hingga pendidikan tinggi. Pada jenjang sekolah dasar, peserta didik mendapatkan mata pelajaran agama Hindu sebanyak 4 jam pelajaran per minggu. Kemudian pada jenjang sekolah menengah pertama dan atas mendapatkan 3 (tiga) jam pelajaran di setiap minggu dan pada jenjang pendidikan tinggi umumnya mata kuliah pendidikan agama Hindu mendapatkan bobot 2 satuan kredit semester (sks).

Kesuksesan pelaksanaan pendidikan agama Hindu tentunya tidak bisa lepas dari peran guru agama Hindu (Yasa, Wijaya, Mahendradhani, \& Supadmini, 2020). Guru agama Hindu memiliki peran untuk merancang pembelajaran, mengelola dan mengevaluasi pembelajaran dan melayani konseling siswa (Uno, 2007). Dengan demikian kualitas guru agama Hindu harus senantiasa dikontrol oleh semua pihak seperti pemerintah, LPTK dan pihak lainnya yang terlibat dalam pendidikan.

Salah satu faktor yang menentukan kualitas guru agama Hindu adalah kinerja dari guru agama Hindu. Kinerja pada dasarnya adalah hasil yang dicapai oleh seseorang menurut ukuran yang berlaku pada pekerjaan yang bersangkutan (Afandi, 2018). Kinerja setiap individu akan mempengaruhi keberhasilan kelompok atau organisasi (Hasibuan \& Silvya, 2019). Bagi guru agama Hindu, kinerjanya dapat diukur melalui kemampuan guru mencapai kompetensi guru dan kemampuan melaksanakan tugas pokok dan fungsi serta tugas tambahan yang diberikan.

Salah satu faktor yang menentukan kinerja guru adalah motivasi berprestasi (Grifin, 2003). Motivasi merupakan tingkat kesediaan dalam mengerahkan segala sumber daya yang dimiliki individu untuk menggapai tujuan yang telah ditetapkan (Setiawan, 2015). Ketika seorang guru agama Hindu memiliki motivasi berprestasi yang tinggi maka mereka akan berupaya memberikan yang terbaik untuk mencapai target yang ditetapkan bahkan melampaui tujuan yang telah ditetapkan. Motivasi berprestasi dipengaruhi oleh beberapa faktor yaitu kebutuhan hidup, kebutuhan masa depan, kebutuhan harga diri dan pengakuan prestasi kerja (Afandi, 2018). Berdasarkan pengalaman peneliti di lapangan, banyak guru agama Hindu berkinerja tinggi namun belum bersertifikat pendidik. Padahal secara teori, guru yang berkinerja tinggi adalah guru yang sudah bersertifikat pendidik karena kinerja itu akan dijadikan acuan dalam mendapatkan tunjangan profesi guru. Dengan demikian, peneliti tertarik untuk melakukan riset tentang korelasi antara motivasi berprestasi dan kinerja guru agama Hindu yang belum bersertifikat pendidik.

\section{METODE}

Penelitian ini tergolong dalam penelitian korelasi yaitu penelitian yang meneliti tentang interaksi dua variabel dan kekuatan interaksinya. (Arikunto, 2006). Varibel yang dikaji dalam penelitian ini adalah motivasi berprestasi dan kinerja guru agama Hindu. Desain penelitian ini adalah penelitian one shot case study dimana diberikan perlakuan terhadap suatu kelompok kemudian diukur hasil dari perlakuan itu (Sugiyono, 2010).

Lokasi penelitian ini adalah di sekolah dasar yang berada di kabupaten Tabanan. Populasi penelitian adalah seluruh guru pengajar mata pelajaran Agama Hindu di jenjang sekolah dasar 
dan belum memiliki sertifikat pendidik. Penentuan sampel dilakukan dengan metode sampel jenuh dimana seluruh anggota populasi dijadikan sampel. Total sampel sebanyak 46 (empat puluh enam) orang.

Instrumen penelitian menggunakan dua buah instrumen yaitu lembar kuisioner motivasi berprestasi dan lembar observasi kinerja guru. Setiap butir instrument berisi rentang skor dari 1 - 5. Kuisioner motivasi berprestasi menggunakan konsep motivasi berprestasi versi McClelland (1988) yang terdiri dari 30 (tiga puluh) butir pertanyaan. Kisi-kisi kuisioner motivasi berprestasi disajikan pada Tabel 1

Tabel 1. Kisi-Kisi Angket Motivasi Berprestasi

\begin{tabular}{|c|c|c|c|c|c|}
\hline No & Variabel & Sub-Variabel & Indikator & Butir & Jumlah \\
\hline \multirow[t]{4}{*}{1} & \multirow{3}{*}{$\begin{array}{l}\text { Motivasi } \\
\text { Berprestasi } \\
\text { (McClelland, } \\
1988 \text { ) }\end{array}$} & $\begin{array}{l}\text { Kebutuhan } \\
\text { Prestasi }\end{array}$ & 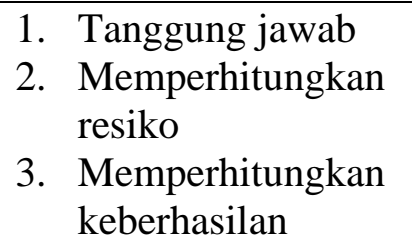 & $\begin{array}{l}1,2.3,4 \\
5,6,7 \\
8,9,10\end{array}$ & $\begin{array}{l}4 \\
3 \\
3\end{array}$ \\
\hline & & $\begin{array}{l}\text { Kebutuhan } \\
\text { Afiliasi }\end{array}$ & $\begin{array}{l}\text { 1. Bersahabat } \\
\text { 2. Perhatian } \\
\text { 3. Bekerja sama } \\
\text { 4. Penyesuaian diri }\end{array}$ & $\begin{array}{l}11,12,13 \\
14,15 \\
16,17 \\
18,19,20\end{array}$ & $\begin{array}{l}3 \\
2 \\
2 \\
3\end{array}$ \\
\hline & & $\begin{array}{l}\text { Kebutuhan } \\
\text { Kekuasaan }\end{array}$ & $\begin{array}{l}\text { 1. Suka } \\
\text { mempengaruhi } \\
\text { 2. Suka } \\
\text { mengendalikan } \\
\text { 3. Sering memberi } \\
\text { saran dan pendapat } \\
\text { 4. Dekat dengan } \\
\text { pimpinan }\end{array}$ & $\begin{array}{l}21,22,23 \\
24,25 \\
26,27 \\
28,29 \\
30\end{array}$ & $\begin{array}{l}3 \\
2 \\
4 \\
1\end{array}$ \\
\hline & Total & & & & 30 \\
\hline
\end{tabular}

Instumen yang baik adalah instrumen yang sudah lulus uji validitas dan reliabilitas (Darmadi, 2011). Oleh karena itu, kuisioner motivasi berprestasi dilakukan kedua uji tersebut. Instrumen dikatakan valid jika memiliki skor uji validitas minimal 0,300 (Darmayanti \& Wijaya, 2020). Hasil pengujian validitas menyatakan bahwa instrumen motivasi berprestasi memiliki skor validitas berkisar 0,810 - 0,968 sehingga seluruh butir instrumen dinyatakan valid. Kemudian hasil pengukuran reliabilitas Alpha Cronbach menunjukkan skor 0,990 sehingga memiliki reliabilitas sangat tinggi.

Kemudian, lembar observasi kinerja guru menggunakan lembar observasi yang dikembangkan oleh Bernai \& Russel (1995). Lembar observasi tersebut terdiri dari 33 butir instrument. Indikator dan kisi-kisi instrument lembar observasi kinerja guru disajikan pada Tabel 2

Tabel 2. Kisi-Kisi Lembar Observasi Kinerja Guru

\begin{tabular}{|l|l|l|l|l|l|}
\hline No & Variabel & Sub-Variabel & Indikator & Butir & Jumlah \\
\hline 1 & Kinerja & Quality & $\begin{array}{l}\text { Kemampuan untuk } \\
\text { mencapai standar dan } \\
\end{array}$ & Guru & tujuan meliputi \\
& Agama & & $\begin{array}{l}\text { 1. Penetapan standar } \\
\text { pembelajaran }\end{array}$ & & \\
& Hindu & & & \\
\hline
\end{tabular}




\begin{tabular}{|c|c|c|c|c|c|}
\hline & $\begin{array}{l}\text { (Bernaidan, } \\
\text { John.H, \& } \\
\text { Russel, } \\
\text { 1995) }\end{array}$ & & $\begin{array}{l}\text { 2. Penetapan standar } \\
\text { kurikulum } \\
\text { 3. Penetapan standar } \\
\text { pelayanan administrasi } \\
\text { 4. Penetapan standar } \\
\text { akademik }\end{array}$ & $1-8$ & 8 \\
\hline 2 & & Quantity & $\begin{array}{l}\text { Kuantitas kegiatan yang } \\
\text { diselesaikan meliputi } \\
\text { 1. Pelaksanaan standar } \\
\text { pembelajaran } \\
\text { 2. Pelaksanaan standar } \\
\text { kurikulum } \\
\text { 3. Pelaksanaan standar } \\
\text { pelayanan administrasi } \\
\text { 4. Pelaksanaan standar } \\
\text { akademik }\end{array}$ & $9-13$ & 5 \\
\hline 3 & & Timeliness & $\begin{array}{l}\text { Kemampuan } \\
\text { memanfaatkan waktu } \\
\text { dengan efektif dan efisien } \\
\text { meliputi : } \\
\text { 1. Tepat waktu } \\
\text { 2. Mengelola kelas } \\
\text { 3. Membimbing siswa } \\
\text { 4. Menciptakan situasi } \\
\end{array}$ & $14-19$ & 6 \\
\hline 4 & & $\begin{array}{l}\text { Cost- } \\
\text { effectiveness }\end{array}$ & $\begin{array}{l}\text { Kemampuan } \\
\text { menggunakan sumber } \\
\text { daya untuk mencapai } \\
\text { tujuan } \\
\text { 1. Efektivitas penggunaan } \\
\text { sarana dan prasarana } \\
\text { yang ada. } \\
\text { 2. Efektivitas penggunaan } \\
\text { sumber daya yang ada } \\
\end{array}$ & $20-22$ & 4 \\
\hline 5 & & $\begin{array}{l}\text { Need for } \\
\text { supervision }\end{array}$ & $\begin{array}{l}\text { Kemampuan bekerja tanpa } \\
\text { diawasi } \\
\text { 1. Melakukan pembinaan } \\
\text { dari supervisor } \\
\text { 2. Pemanfaatan supervisor }\end{array}$ & $23-25$ & \\
\hline 6 & & $\begin{array}{l}\text { Interpersonal } \\
\text { impact }\end{array}$ & $\begin{array}{l}\text { Kemampuan menjaga } \\
\text { nama baik dan interaksi } \\
\text { sosial positif dengan rekan } \\
\text { kerja }\end{array}$ & $26-33$ & 10 \\
\hline & Total & & & & 33 \\
\hline
\end{tabular}

Lembar observasi ini juga dilakukan pengujian validitas dan reliabilitasnya. Hasil uji validitas menyatakan tidak ada butir instrument yang memiliki skor lebih rendah dari 0,72 sehingga seluruh instrument dinyatakan valid. Kemudian hasil pengujian reliabilitas menunjukkan skor 0,990 sehingga memiliki reliabilitas tinggi. 
Analisis data dilakukan secara deskriptif dan statistik inferensial. Analisis skor motivasi berprestasi dan kinerja guru dilakukan melalui rumus berikut :

$$
\text { Skor }=\frac{\text { skorangket }}{\text { skortotal }} \times 100
$$

Skor motivasi berprestasi dan kinerja guru tersebut kemudian digolongkan berdasarkan tabel kriteria yang telah ditetapkan. Kriteria skor motivasi berprestasi dan kinerja guru dapat dilihat pada Tabel 3

Tabel 3. Tabel Kriteria Skor Motivasi Berprestasi dan Kinerja Guru
\begin{tabular}{|c|c|}
\hline Skor & Kriteria \\
\hline $00,00-20,00$ & Sangat Rendah \\
\hline $21,00-40,00$ & Rendah \\
\hline $41,00-60,00$ & Cukup \\
\hline $61,00-80,00$ & Tinggi \\
\hline $81,00-100,00$ & Sangat Tinggi \\
\hline
\end{tabular}

(Sumber : Yasa \& Wijaya, 2020b)

Uji statistik inferensial dilakukan dengan teknik korelasi product moment. Sebelum dilakukan uji korelasi product moment dilakukan terlebih dahulu uji prasyarat analisis yaitu uji normalitas dan uji linearitas. Uji tersebut dilakukan dengan taraf signifikasi 5\% dan dikerjakan dengan bantuan program SPSS 17.0 for Windows. Hipotesis yang diuji adalah :

$\mathrm{H}_{\mathrm{o}}$; tidak terdapat hubungan yang signifikan antara motivasi berprestasi dengan kinerja guru $\mathrm{H}_{\mathrm{a}}$; terdapat hubungan yang signifikan antara motivasi berprestasi dengan kinerja guru.

Hipotesis alternatif $\left(\mathrm{H}_{\mathrm{a}}\right)$ diterima jika harga $\mathrm{T}_{\text {hitung }}>\mathrm{T}_{\text {tabel. }}$ Kemudian dilakukan juga pengujian kuat lemahnya hubungan antara variabel motivasi kerja dengan kinerja guru dengan membandingkan harga $\mathrm{r}_{\mathrm{xy}}$ dengan harga koefisien korelasi dari Guilford Emperical Rulesi yang disajikan pada Tabel 4.

Tabel 4. Tingkat Keeratan Hubungan Variabel

\begin{tabular}{|c|c|}
\hline Harga $\mathbf{r}_{\mathbf{x y}}$ & Tingkat Keeratan \\
\hline $0,00-0,20$ & Sangat lemah \\
\hline $0,21-0,40$ & Lemah \\
\hline $0,41-0,70$ & Sedang \\
\hline $0,71-0,90$ & Kuat \\
\hline $0,91-1,00$ & Sangat kuat \\
\hline
\end{tabular}

(Sumber : Abidin \& Ijrah, 2018)

Sebelum dilakukan pengujian hipotesis, terlebih dahulu dilakukan uji normalitas data dan uji linearitas data yang dilakukan dengan bantuan program SPSS 17.0 for Windows dengan taraf signifikansi 5\% (0,05).

\section{HASIL DAN PEMBAHASAN}

Hasil penelitian yang ditampilkan berupa skor motivasi berprestasi dan skor kinerja guru. Data skor motivasi berprestasi dan kinerja guru disajikan pada Tabel 5 dan Tabel 6

Tabel 5. Data Skor Motivasi Berprestasi

\begin{tabular}{|c|l|c|}
\hline No & \multicolumn{1}{|c|}{ Jenis Skor } & Skor \\
\hline 1 & Skor Rata-Rata & 74,66 \\
\hline 2 & Skor Tertinggi & 84,66 \\
\hline 3 & Skor Terendah & 54,66 \\
\hline
\end{tabular}


Tabel 6. Data Skor Kinerja Guru

\begin{tabular}{|c|l|c|}
\hline No & \multicolumn{1}{|c|}{ Jenis Skor } & Skor \\
\hline 1 & Skor Rata-Rata & 73,00 \\
\hline 2 & Skor Tertinggi & 84,00 \\
\hline 3 & Skor Terendah & 55,00 \\
\hline
\end{tabular}

Data pada Tabel 5 dan 6 menyatakan bahwa skor motivasi beprestasi guru berada pada rentang 54,66 hingga 84,66 sedangkan skor kinerja guru berada pada rentang 55,00 - 84,00. Jika ditinjau berdasarkan kriteria pada tabel 3, maka skor rata-rata untuk motivasi berprestasi dan kinerja guru berada pada kategori tinggi. Kemudian skor terendah kedua aspek tersebut berada di kriteria cukup dan skor tertinggi berada di kriteria sangat tinggi. Hal ini menandakan bahwa tidak satupun guru agama Hindu di jenjang sekolah dasar (SD) yang belum bersertifikat pendidik memiliki kinerja dan motivasi yang rendah.

Kemudian dilakukan pula penggolongan skor kinerja guru dan motivasi berprestasi ke dalam kriteria yang sudah ditetapkan. Penggolongan tersebut disajikan pada Tabel 7

Tabel 7. Penggolongan Skor Motivasi Berprestasi dan Kinerja Guru

\begin{tabular}{|l|c|c|c|c|c|c|}
\hline \multirow{2}{*}{ No } & Rentang Skor & \multirow{2}{*}{ Kriteria } & \multicolumn{2}{c|}{$\begin{array}{c}\text { Motivasi } \\
\text { Berprestasi }\end{array}$} & \multicolumn{2}{c|}{ Kinerja Guru } \\
\cline { 4 - 6 } & & & f & \% & f & \% \\
\hline 1 & $00,00-20,00$ & Sangat Rendah & - & - & - & - \\
\hline 2 & $21,00-40,00$ & Rendah & - & - & - & - \\
\hline 3 & $41,00-60,00$ & Cukup & 5 & $10,87 \%$ & 7 & $15,21 \%$ \\
\hline 4 & $61,00-80,00$ & Tinggi & 36 & $78,26 \%$ & 39 & $84,79 \%$ \\
\hline 5 & $81,00-100,00$ & Sangat Tinggi & 5 & $10,87 \%$ & - & - \\
\hline
\end{tabular}

Data pada Tabel 7 menyatakan bahwa sebagian besar atau lebih dari 50\% (lima puluh persen) anggota sampel memiliki motivasi berprestasi dan kinerja berada pada kriteria yang tinggi. Namun, data tersebut juga menunjukkan bahwa belum ada satupun anggota sampel yang memiliki kinerja dengan kriteria sangat tinggi. Selanjutnya dilakukan tahap pengujian hipotesis. Sebelum dilakukan uji hipotesis terlebih dahulu dilakukan uji normalitas dan uji linearitas. Hasil uji normalitas disajikan pada Tabel 8

Tabel 8. Uji Normalitas Kolmogorov Smirnov

\begin{tabular}{|l|c|c|}
\hline \multirow{2}{*}{ Variabel } & \multicolumn{2}{c|}{ Kolmogorov-Smirnov } \\
\cline { 2 - 3 } & Statistik & Sig \\
\hline Motivasi Berprestasi Guru & 0,830 & 0,496 \\
\hline Kinerja guru & 1,298 & 0,069 \\
\hline
\end{tabular}

Tabel 8 menunjukkan bahwa hasil uji normalitas data motivasi berprestasi dan kinerja guru memiliki signifikansi diatas $0,05(5 \%)$ yang artinya data tersebut berdistribusi normal. Kemudian dilakukan pula uji linearitas antara motivasi berprestasi dan kinerja guru yang dilakukan dengan uji ANAVA. Hasil uji tersebut disajikan pada Tabel 9

Tabel 9. Hasil Analisis ANAVA

Dependent Variable: Kinerja Guru

\begin{tabular}{|c|c|c|c|c|c|c|c|}
\hline \multirow{2}{*}{ Equation } & \multicolumn{5}{|c|}{ Model Summary } & \multicolumn{2}{c|}{ Parameter Estimates } \\
\cline { 2 - 8 } & R Square & F & df1 & df2 & Sig. & Constant & b1 \\
\hline Linear & .895 & 373.232 & 1 & 44 & .000 & 10.184 & .994 \\
\hline
\end{tabular}

The independent variable is Motivasi Berprestasi. 
Data pada Tabel 9 menyatakan bahwa harga signifikansi di bawah 0,05 yang artinya terdapat hubungan yang linear antara motivasi berprestasi dan kinerja guru. Kemudian dilakukan uji hipotesis dengan menggunakan koefisien korelasi product moment yang hasilnya dapat disajikan pada Tabel 10

Tabel 10. Hasil Pengujian Koefisien Korelasi Product Moment

\begin{tabular}{|c|c|c|c|}
\hline \multicolumn{2}{|c|}{} & Motivasi Berprestasi & Kinerja Guru \\
\hline Motivasi Berprestasi & Pearson Correlation & 1 & 0,715 \\
\cline { 2 - 4 } & Sig & & 0,000 \\
\cline { 2 - 4 } & $\mathrm{N}$ & 46 & 46 \\
\hline \multirow{4}{*}{ Kinerja Guru } & Pearson Correlation & 0,715 & 1 \\
\cline { 2 - 4 } & Sig & 0,000 & 46 \\
\cline { 2 - 4 } & $\mathrm{N}$ & 46 & \multicolumn{2}{c}{} \\
\hline
\end{tabular}

Berdasarkan data pada Tabel 10 terlihat bahwa harga signifikansi di bawah 0,05 yang artinya hipotesis nol $\left(\mathrm{H}_{\mathrm{o}}\right)$ ditolak dan hipotesis alternatif $\left(\mathrm{H}_{\mathrm{a}}\right)$ diterima sehingga dapat disimpulkan bahwa terdapat hubungan yang signifikan antara motivasi berprestasi dengan kinerja guru agama hindu di sekolah dasar (SD) yang belum bersertifikat pendidik. Data pada tabel tersebut juga menunjukkan besaran koefisien korelasi product moment $\left(\mathrm{r}_{\mathrm{xy}}\right)$ sebesar 0,715 . Jika ditinjau berdasarkan tingkat keeratan hubungan variabel pada Tabel 4, maka tingkat hubungan antara motivasi berprestasi dengan kinerja guru adalah kuat.

Hasil penelitian menunjukkan bahwa terdapat korelasi yang signifikan antara motivasi berprestasi dengan kinerja guru agama Hindu jenjang sekolah dasar (SD) yang belum bersertifikat pendidik. Hal itu ditinjau berdasarkan hasil analisis korelasi product moment yang menunjukkan harga signifikansi $<0,05$. Selain itu hasil analisis nilai $\mathbf{r}_{x y}$ menunjukkan skor 0,715 yang menunjukkan adanya tingkat korelasi yang kuat antara motivasi berprestasi dengan kinerja guru. Penelitian ini sudah sejalan dengan berbagai penelitian lainnya misalnya penelitian tentang Pengaruh Motivasi Kerja dan Lingkungan Kerja Terhadap Kinerja Karyawan. Hasil penelitian itu menyatakan bahwa motivasi kerja berpengaruh dengan kinerja karyawan (Bachtiar, 2012).

Keterkaitan antara motivasi dengan kinerja dijelaskan bahwa kinerja adalah hasil dari motivasi dengan kemampuan (Mitchell \& Larson, 1987). Seorang guru yang memiliki motivasi berprestasi tinggi dan memiliki kemampuan yang baik maka akan dapat bekerja secara profesional. Namun, jika salah satu dari keduanya tidak dimiliki oleh seorang guru maka akan sulit pula bekerja secara profesional. Oleh karena itu, sangat penting bagi seorang guru untuk senantiasa memiliki motivasi berprestasi yang baik serta senantiasa meningkatkan kemampuannya dalam bidang pendidikan.

Klinger dan Nitbandia (1985) berpendapat bahwa produktivitas dan kinerja yang baik akan dapat dicapai dari motivasi berprestasi dan dikombinasikan dengan usaha yang tekun. Di samping itu, kondisi kerja juga turut berhubungan dalam menentukan efisiensi dan efektivitas seorang individu dalam berkinerja. Kinerja guru yang baik akan memberikan dampak yang positif bagi perkembangan pendidikan selanjutnya dari organisasi (Syarifuddin, 2007). Selain itu jika guru sudah berkinerja baik maka akan menguntungkan peserta didik karena akan terfasilitasi dalam mengembangan potensi pada dirinya (Mariana, 2018).

Jika dikaitkan dengan masing-masing aspek variabel maka dapat dikaji bahwa adanya saling keterkaitan. Misalnya antara faktor kebutuhan afiliasi tentunya berkaitan dengan interpersonal impact. Seorang guru tentunya agar berkinerja baik tidak bisa bertindak secara individu melainkan membutuhkan bantuan rekan sejawatnya. Kemudian kebutuhan prestasi tentunya akan mempengaruhi aspek quantity, quality dan timeliness. Semakin tinggi kebutuhan prestasi maka ketercapaian aspek tersebut juga akan semakin tinggi. 
Kekuatan untuk bertindak bergantung pada kekuatan ekspektasi di mana tindakan itu diikuti oleh konsekuensi dan kemenarikan tindakan pelakunya. Faktor-faktor yang memengaruhi persepsi ekspektasi guru adalah (1) penghargaan diri, (2) keberhasilan menjalankan tugas, (3) bantuan yang diterima guru dari pimpinan, (4) informasi yang diperlukan untuk menyelesaikan tugas, dan (5) materi dan ketersediaan perlengkapan kerja (Kreitner \& Kinikci, 2014). Kreitner dan Kinicki memandang bahwa harapan sebagai fungsi nilai yang dipersepsi dengan penghargaan yang kemungkinan diterima guru. Guru harus menunjukkan usaha yang lebih jika meyakini akan memeroleh penghargaan yang bermanfaat setelah melaksanakan dan menyelesaikan pekerjaannya. Ada empat cara yang dapat dilakukan oleh kepala sekolah dan pengampu kebijakan dalam mengaitkan kinerja guru dengan penghargaan yang bermanfaat, yaitu (1) merumuskan standar kinerja para guru, (2) memerlukan hasil penilaian kinerja guru yang valid dan akurat, (3) melakukan penilaian dengan kinerja guru untuk memberikan penghargaan yang berbeda-beda, dan (4) mengidentifikasikan jenis penghargaan yang bernilai bagi para guru. Gordon (1990) menyatakan bahwa jika manajer memiliki harapan yang tinggi dengan bawahannya, maka kinerja para guru akan diusahakan untuk mencapai ekspektasi itu. Oleh sebab itu, manajer yang tertarik pada produktivitas yang tinggi hendaknya mendorong pengembangan para guru agar memiliki kinerja yang tinggi, mengembangkan karier sehingga mendapat kepuasan pribadi. Manajer yang efektif selalu membangkitkan ekspektasi yang tinggi para guru untuk membangun kepercayaan diri sendiri agar kinerjanya menjadi tinggi (Syarifuddin, 2007).

\section{SIMPULAN}

Berdasarkan uraian pembahasan diatas dapat disimpulkan bahwa terdapat hubungan yang signifikan antara motivasi berprestasi dengan kinerja guru agama Hindu jenjang sekolah dasar yang belum bersertifikat pendidik. Tingkat hubungan kedua variabel itu tergolong kuat. Oleh karena itu penting halnya bagi kepala sekolah dan pemerintah untuk selalu memotivasi guru khususnya guru agama Hindu agar senantiasa memiliki motivasi berprestasi tinggi sehingga kinerja guru tetap tinggi. Kinerja guru yang tinggi nantinya akan berimplikasi dengan kualitas pembelajaran Agama Hindu.

\section{DAFTAR PUSTAKA}

Abidin, Z., \& Ijrah, S. (2018). Hubungan Motivasi Belajar Dengan Hasil Belajar Pada Siswa Kelas V SD Negeri Gugus IV Kecamatan Banuhampu Kabupaten Agam. Jurnal Inovasi Pendidikan Dan Pembelajaran Sekolah Dasar, 2(2), 21-29.

Afandi. (2018). Manajemen Sumber Daya Manusia. Pekanbaru: Zanafa Publishing.

Arikunto, S. (2006). Prosedur Penelitian. Jakarta: Rineka Cipta.

Bachtiar, D. (2012). Pengaruh Motivasi dan Lingkungan Kerja Terhadap Kinerja Karyawan. Management Analysis Journal, 1(1), 1-6.

Bernaidan, John.H, \& Russel, J. (1995). Human Resources Management. Singapore: McGraw Hill, Inc.

Darmadi, H. (2011). Metode Penelitian Pendidikan. Bandung: Alfabeta.

Darmayanti, N. W. S., \& Wijaya, I. K. W. B. (2020). Evaluasi Pembelajaran IPA. Denpasar: Penerbit Nila Cakra.

Grifin. (2003). Manajemen. Jakarta: Penerbit Erlangga.

Hasibuan, J. S., \& Silvya, B. (2019). Pengaruh Disiplin Kerja dan Motivasi Terhadap Kinerja Karyawan. Prosiding Seminar Nasional Multidisiplin Ilmu, 134-147. Banda Aceh: LPPM Universitas Serambi Mekkah.

Kreitner, R., \& Kinikci, A. (2014). Perilaku Organisasi. Jakarta: Salemba Empat.

Mariana, I. M. A. (2018). Pengantar Perencanaan Pembelajaran di Sekolah Dasar. Denpasar: Lembaga Penjaminan Mutu Pendidikan Bali.

McClelland, D. (1988). Human Motivation. Cambridge: Cambridge University Press. 
Mitchell, R., \& Larson. (1987). People in Organization: An Introduction to Organizational Behavior. New York: McGraw-Hill. Inc.

Setiawan, K. C. (2015). Pengaruh Motivasi Kerja Terhadap Kinerja Karyawan Level Pelaksana Di Divisi Operasi PT. PUSRI PALEMBANG. Psikis-Jurnal Psikologi Islami, 1(2), 4353.

Sugiyono. (2010). Metode Penelitian Pendidikan Pendekatan Kuantitatif, Kualitatif dan R\&D. Bandung: Penerbit Alfabeta.

Syarifuddin. (2007). Hubungan Antara Strategi Manajemen Konflik Organisasi Oleh Kepala Sekolah, Iklim Sekolah, Insentif Guru, Dan Motivasi Berprestasi Guru Dengan Kinerja Guru Sekolah Menengah Kejuruan Negeri Di Sulawesi Selatan. Universitas Negeri Malang.

Uno, H. B. (2007). Profesi Kependidikan. Jakarta: Bumi Aksara.

Yasa, I. M. W., \& Wijaya, I. K. W. B. (2020a). Kompetensi Guru Agama Hindu Yang Belum Bersertifikat Pendidik. Jurnal Purwadita, 4(2), 181-186.

Yasa, I. M. W., \& Wijaya, I. K. W. B. (2020b). Profil Kinerja Guru Agama Hindu Yang Sudah Bersertifikat Pendidik. Jurnal Kamaya, 3(3), 319-326.

Yasa, I. M. W., Wijaya, I. K. W. B., Mahendradhani, I. G. A. A. R., \& Supadmini, N. K. (2020). Motivasi Berprestasi Guru Agama Hindu Jenjang SMP Yang Sudah Bersertifikat Pendidik. Jurnal Cetta, 3(3), 463-471. 